\title{
Paediatric nurses' attitudes towards the promotion of healthy eating
}

\author{
Holly Blake and Joanna Patterson \\ University of Nottingham \\ Accepted for publication: December 2014
}

\begin{abstract}
This study assessed paediatric nurses' attitudes towards promoting healthy eating and their opinions regarding nurses as role models for health. In all, 67 nurses from 14 wards at an acute hospital trust completed questionnaires on weight, diet, physical activity, self- efficacy and attitudes towards nurses as role models for health. Fortyeight percent felt that they could incorporate health promotion into their patient care better, and $84 \%$ believed that nurses should present themselves as role models for health. Nurses felt that their own health behaviours influenced the quality of their care: $77 \%$ reported that patients and families would heed advice better from those who appeared to follow it themselves, and $48 \%$ reported difficulties in promoting health behaviours they did not adhere to themselves. These views were inconsistent with their own lifestyle choices, since one third of respondents did not meet physicalactivity guidelines, almost half were an unhealthy weight, and the majority did not consume five portions of fruits/vegetables per day. Paediatric nurses identified barriers and facilitators to promoting healthy eating. Education, training and access to evidence-based resources may help to increase paediatric nurses' confidence to promote healthy eating to children and their families. Hospital workplaces should make provision to support nurses who seek to improve their own health.
\end{abstract}

Key words: Paediatric; Nurses; Health promotion; Health behaviours; Role models 


\section{Introduction}

Encouraging children and their families to establish healthy eating behaviours is vital to the prevention of childhood obesity. While all nurses should share a commitment to health promotion (Miller et al, 2008), there is a debate as to whether nurses are better equipped to deliver healthy-lifestyle advice to patients and their families if they engage in healthy-lifestyle behaviours themselves, and act as positive role models for health promotion (Blake, 2013).

As advocates for health, nurses are unavoidably role models to the general public and, as such, it has been argued that effective role modelling should mean 'practising what you preach' (Borchardt, 2000; Hicks et al, 2008). This hinges on the premise that nurses should follow healthy behaviours themselves if they are to expect their patients and their patients' families to do the same (Borchardt, 2000; Rush et al, 2005; Miller et al, 2008).

Yet the reality is that a significant proportion of nurses are overweight or obese, are not consuming their 'five-a-day' of fruits/vegetables, are regularly consuming foods that are high in fat and sugar, and are not engaging in recommended daily levels of physical activity (150 minutes of moderate aerobic activity per week) (Nursing Times, 2008; Department of Health (DH), 2009; Blake et al, 2011; Malik et al, 2011; Blake et al, 2012; Royal College of Physicians (RCP), 2013). For some nurses, such factors negate the potential for positive role-modelling of healthy behaviours. Indeed, obese NHS staff have been subject to criticism in the House of Lords for being poor role models for those patients who are trying to lose weight (Nursing Times, 2012). 
Of course, nurses are no less exposed to the same temptations and risks of falling into unhealthy lifestyle habits than the general public (Borchardt, 2000; Nahm et al, 2012). The expectation that they should be role models for health too may add pressure to what is already widely regarded as a stressful profession (Nursing Times, 2008). For some, being an imperfect, 'realistic' role model for health promotion is as valuable as being a perfect role model because 'imperfections' can be used positively in healthpromotion practice (Rush et al, 2005). For example, nurses who have struggled to make lifestyle- behaviour changes may potentially feel better-equipped to empathise with their patients' perspectives and efforts (Rush et al, 2005). Nurses' views on these issues will inevitably influence their actions, although we currently know little about the perspectives of those at the heart of the debate.

This study had three aims:

[1] To assess paediatric nurses' attitudes towards promoting healthy eating to children and families

[2] To assess paediatric nurses' opinions regarding nurses as role models for health behaviours

[3] To ascertain whether there is a relationship between nurses' own health behaviours and body composition, and their attitudes and opinions.

\section{Methods}

Ethical approval was granted by the local medical school research ethics committee, and the protocol was approved by the local NHS trust research governance board. A 
questionnaire survey was distributed to 291 paediatric nurses on 14 ward areas on a single site of an acute NHS trust. Nurses were provided with a pre-addressed envelope for their questionnaires' return in the internal mail (to an independent researcher). Completion informed consent for participation. Participants were informed that their participation was voluntary and anonymous. They were invited to return the survey within 12 weeks and a reminder note was distributed to ward areas after 8 weeks.

\section{Questionnaire measures}

Participants were asked to provide their gender, age category, length of time since qualification, employment status (full-time or part-time), job role (sister, junior sister or staff nurse), and height and weight measurements, from which body mass index (BMI) was determined with the calculation $\mathrm{kg} / \mathrm{m} 2$.

Participants were asked to report whether they consumed five portions of fruits and/or vegetables per day (yes/no). The transtheoretical model 'Physical Activity Stages of Change Scale' (Marcus et al, 1992) was used to determine nurses' level of engagement in the recommended guidelines for daily physical activity (150 minutes of moderate-intensity physical activity per week). Participants were also asked to complete the 'Generalised Self-Efficacy Scale' (Schwarzer and Jerusalem, 1995). The scale contains a set of ten statements, each relating to self-efficacy (i.e. confidence in,

or the belief that, one's actions are responsible for successful outcomes). Participants were asked to consider the statements and to score each one with reference to themselves. Response categories were: 1='not true at all', 2='hardly true', 
3='moderately true', 4='exactly true'. A higher cumulative score indicates greater self-efficacy.Two additional statements were included, which were aimed at underpinning participants' level of confidence specifically in the promotion of healthy eating to children and their families.

Participants were asked to complete a series of 11 items about their opinions and attitudes towards paediatric nurses as role models for health promotion with children and their families with particular regard to healthy eating (Box 1). Since no standardised measure was available, these items were generated by the researchers based on relevant issues identified in the literature, and were reviewed and amended following discussion with five nurse educators. Response categories were: 'strongly agree', 'agree', 'neutral', 'disagree' or 'strongly disagree'. Participants were asked to score their level of concern about obesity in the general population and in childhood, on a scale of 0 (no concern) to 10 (greatest possible concern). Minor amendments to the questionnaire survey were made following pilot testing with ten pre-registered nurses. Data were analysed with SPSS for Windows (version 21). Analyses included descriptive statistics, chi-square tests and Mann-Whitney U tests.

\section{Results}

\section{Participant characteristics}

Sixty-seven paediatric nurses completed a questionnaire (response rate $23 \%$ ). Sample characteristics were broadly comparable with those of all paediatric nurses employed at the trust. The majority of the sample was female (sample: $88 \%$ female; trust: $96 \%$ 
female). Age ranged from 18 to 65 years, with the greatest proportion of nurses falling between 18 and 35 years, which is comparable with the age range of those employed at the trust (sample: $60 \%$ aged $18-35$; trust: $51 \%$ aged $18-35$ ).

Respondents included staff nurses $(67 \%, \mathrm{n}=45)$, junior sisters $(25 \%, \mathrm{n}=17)$ and sisters $(8 \%, \mathrm{n}=5)$, who had been employed between 3 months and 31.5 years (sample mean $=9.8$ years, $S D=103.3$; trust average 9.8 years $)$. Of the sample, $16 \%(n=11)$ had high self-efficacy on the Generalised Self-Efficacy Scale. BMI ranged from 18.0 to $47.9($ mean $=25.6, \mathrm{SD}=5.5) ; 45 \%(\mathrm{n}=30)$ were overweight or obese (underweight $=2 \%$; overweight $=31 \%$; obese $=13 \%)$. Seventy-nine percent of participants $(n=53)$ reported that they did not consume five portions of fruits/vegetables per day. Thirty percent $(n=20)$ reported that they did not get the Government's recommendation of 150 minutes of moderate-intensity exercise per week.

Participants expressed concern about childhood obesity, with $42 \%(n=28)$ scoring their concern at 10 out of 10 (indicating maximum concern), and the majority ( $93 \%$, $\mathrm{n}=62$ ) scoring their concern as 7 or more out of 10 (indicating high or maximum level of concern).This concern was evident across the sample, irrespective of the paediatric nurse's own body composition or health behaviours.

The majority of participants $(88 \%, \mathrm{n}=59)$ agreed that health promotion was important and should be part of a paediatric nurse's job role. Those who were hesitant to promote health were more likely to be overweight or obese and/or have poor diet and/or low levels of physical activity. They provided reasons such as: [i] the need for training and resources; [ii] lack of time to promote health; 
[iii] the perception that health promotion was not relevant once a child was in hospital' [iv] the perception that health promotion was less appropriate in some clinical areas than in others; [v] the perception that health promotion would be more effectively delivered by a different health professional (i.e. not a nurse).

Nearly three-quarters of nurses $(72 \%, \mathrm{n}=48)$ felt that their health-promotion practices with children and their families would influence the attitudes and actions of student nurses ('next generation' NHS staff) towards health promoting. The nurses who were less likely to agree with this were more likely to be overweight or obese.

Respondents identified a range of barriers and facilitators to promoting healthy eating among children and their families (Table 1). Only $18 \%(n=12)$ believed that a sufficient level of healthy-eating promotion was undertaken in their areas of work. Almost half of the nurses $(48 \%, n=32)$ felt that they personally could better incorporate healthy eating promotion into their care, including nurses with healthier and poorer body composition and lifestyle behaviours. Nurses with high general selfefficacy were significantly more likely to feel confident in promoting healthy eating to children $(p<0.05)$ and their families $(p<0.01)$ than those with moderate selfefficacy.

\section{Nurses' attitudes towards being role models for health}

Most respondents felt that paediatric nurses should present themselves as role models for health $(84 \%, \mathrm{n}=56)$, although half of respondents felt that paediatric nurses in general are not presently good role models for health to patients and their families $(49 \%, n=33)$. Over three-quarters of respondents felt that patients and their families 
would be more likely to listen to their health- promotion advice if they appeared to follow it themselves $(70 \%, n=47)$. Almost half of the nurses reported that they found it difficult to promote health behaviours if they did not carry out the same behaviours themselves $(48 \%, n=32)$. Just over $70 \%(n=47)$ of respondents agreed that paediatric nurses should have a healthy diet and exercise regularly themselves. These respondents tended to be those of healthy weight, rather than those who were underweight, overweight or obese ( $62 \%$ compared with $38 \%$, respectively), although this trend did not reach statistical significance.

Regarding their own health status, $58 \%(\mathrm{n}=39)$ of the nurses felt that their physical appearance affected the way they were perceived as a nurse and $52 \%(\mathrm{n}=35)$ felt that being an ideal weight was important to their role as a paediatric nurse. However, nurses who were underweight, overweight or obese were significantly less likely to agree that their physical appearance $(\mathrm{p}<0.001)$ or weight $(\mathrm{p}<0.001)$ was important than those who had a healthy weight.

The majority of nurses $(82 \%, \mathrm{n}=55)$ did not feel under pressure to be a 'perfect' role model for health; indeed, three-quarters of respondents $(78 \%, n=52)$ believed that patients may find it easier to connect with them if they viewed their health behaviours as those of a 'real' person rather than an ideal.

\section{Discussion}

As advocates for health, nurses are well placed to provide health promotion advice and, as such, to contribute to managing the obesity epidemic. Given the worldwide 
concern about rising childhood obesity and associated life-long consequences for physical and psychosocial wellbeing, paediatric nurses are in a unique position to provide health promotion advice specifically to children and their families, although their opinions on this issue are not well understood.

This study has ascertained the opinions of paediatric nurses towards the prevalence of obesity in children, their role in promoting healthy eating to children and their families, and their attitudes towards nurses being role models for health. Paediatric nurses showed a genuine concern for the high and rising levels of obesity in children. They felt that health promotion should be a part of their role as a paediatric nurse, with most of the nurses feeling that healthy-eating promotion in their area of work was not sufficient, and half feeling that they could personally do more to promote healthy eating with children (and families) in their care. Although most nurses did not feel under particular pressure to be perfect role models, there was a prevailing attitude that nurses in general should be role models for health, and should engage in positive lifestyle behaviours themselves. This is consistent with the attitudes of preregistered nurses in all fields of nursing (Chalmers et al, 2002; Blake and Harrison, 2013). However, many believed that paediatric nurses are not currently good role models for health for children and families in their care. Indeed, unhealthy lifestyle behaviours were relatively prevalent in this sample, with a third of respondents self-reporting that they were not physically active enough to benefit their own health; almost half being an unhealthy weight; and the majority not eating five portions of fruits or vegetables per day. This pattern has been found in other nursing and healthcare cohorts $(\mathrm{DH}$, 2009; Blake et al, 2011; Malik et al, 2011; Blake et al, 2012). Therefore, paediatric nurses' own lifestyle behaviours (e.g. diet, physical activity, weight status) appear to 
be inconsistent with their level of concern about population obesity and incongruent with their attitudes towards the importance of nurses being role models for health. This form of 'cognitive dissonance', between health-related [oisjbehaviour or health status and beliefs, has emerged among preregistered nurses in all branches of nursing (Blake and Harrison, 2013).

Although a large proportion of the paediatric nurses felt that patients may connect better with a 'real' rather than ideal nurse, there was a strong recognition that a nurse's own health behaviours would probably affect the quality of patient care. The mechanism for this was twofold: the patient's perceptions of the nurse, and the nurse's willingness to deliver health promotion to patients and their families. First, the majority of paediatric nurses believed that children and their families would be more likely to follow lifestyle advice from a nurse who was a healthy role model, and this included a recognition that their own physical appearance and weight status would carry some influence in how they were perceived by their patients. Second, a large proportion of paediatric nurses felt that they would find it difficult to promote healthy lifestyles to children and their families when they were not, or did not outwardly appear to be, heeding their own advice. Nurses reported that their own positive health behaviours were a facilitator for promotion of healthy eating with children and their families. But, conversely, they reported that their own engagement in negative health behaviours was a barrier to effective health promotion with their patients.

Paediatric nurses' beliefs support the idea that good role modelling concerns 'practising what you preach' (Borchardt, 2000; Rush et al, 2005; Miller et al, 2008) in the eyes of children and their families in their care, and also preregistered paediatric 
nursing students who may be observing their practice. These beliefs often conflict with their personal health status and health-behaviour choices. Despite the clear benefits of healthy role-modelling and paediatric nurses' beliefs that their own lifestyle choices do exert an influence on patient care, it is recognised that there are particular challenges associated with the nursing profession in general, which may act as barriers to making healthy lifestyle choices. For example, shift patterns, long hours, demanding work and high levels of stress can engender unhealthy coping strategies and negatively affect nurses' ability to sustain healthy eating and exercise patterns (Friis et al, 2007; Miller et al, 2008; Nursing Times, 2008).

The majority of paediatric nurses in this study had only moderate levels of selfefficacy. Higher self-efficacy increases one's confidence in successfully executing a behaviour (Bandura, 1986). There is a strong relationship between paediatric nurses' self-efficacy and their professional practice, behaviours and performance (Manojlovich, 2005); it follows that nurses are more likely to undertake a healthy behaviour themselves if they have higher self-efficacy. In this sample, paediatric nurses who had high self-efficacy were more likely to consume five portions of fruits/vegetables a day and engage in recommended levels of physical activity than those with lower levels of self-efficacy. Furthermore, paediatric nurses with high selfefficacy reported feeling at least moderately confident in promoting healthy eating to the children and families that they care for. This finding supports previous studies that have demonstrated that nurses with higher self-efficacy are more likely to have a better attitude towards, and more confidence in, promoting health to others (Mayer et al, 2005). 


\section{Recommendations}

Research is needed for further investigation of paediatric nurses' perceptions of their own health and its relationship with health-promoting practices with children and their families, and to determine how they might best be supported through the workplace to make positive lifestyle changes - for example, encouraging nurses to be more active by using the stairs rather than the lifts; ensuring healthy food is available on the ward or department and in staff restaurants and vending machines; encouraging regular work breaks for nurses to eat; and providing them with access to weightmanagement support and options may be simple but effective methods of fostering positive lifestyle choices for nurses and potentially improving their health.

With ongoing attention to the health and wellbeing of NHS employees (DH, 2009), workplace-wellness schemes in NHS settings are on the increase and have shown potential for health improvement (Bull et al, 2008; Blake et al, 2013) through individual and group-level health interventions and campaigns aiming to monitor health, increase physical activity, improve diet, promote smoking cessation, reduce stress and support positive mental wellbeing. Efforts need to be made to build selfefficacy for engaging in healthy behaviours and self-efficacy for health promotion among paediatric nursing staff - particularly those in less senior roles, since selfefficacy levels increased with seniority, and lower confidence for health promotion was reported more frequently among those in less senior roles.

Paediatric nurses reported a range of barriers to successful promotion of healthy eating to children and their families. Lack of time was reported to be an important 
barrier to delivery of health promotion. Nurses proposed that for health promotion to be effectively delivered, they need health promotion to be identified as a priority task by senior staff; this is relevant as nurses have previously described their work environment as being unsupportive of health-promotion activities (Rash, 2008).

In this study, some paediatric nurses indicated that they found healthy eating of a child a difficult subject to raise with the parents, who are the 'gatekeepers' of a child's health behaviour. This feeling was more evident in those paediatric nurses who were overweight or obese (particularly where obesity was also evident in the children or parents). Paediatric nurses explicitly identified a need for more information and training regarding the promotion of healthy eating in children, most notably for those with less experience of, or low confidence in, health promotion.

For health professionals, evidence-based and dietician- supported interprofessional training shared between multiple agencies may help to address this need, raising awareness of health professionals' responsibilities regarding healthy-eating promotion; education on the need to integrate health promotion activities within care; how best to communicate healthy eating strategies with children and families; and where to seek support. This would complement the Government's aim for better integration and partnership between services involved with children (Department for Education and Skills (DfES), 2003; DH, 2011). As paediatric nurses demonstrate strong opinions and attitudes in line with the ideal, but do not always execute behaviours that are consistent with their beliefs, training should include practical applications (e.g. creative application exercises and scenarios) that reinforce healthpromotion behaviours (Rash, 2008) and provide support for those with less 
experience. Evidence-based resources and details of local and national initiatives for healthy eating in children should be available to paediatric nurses to give to patients and their families where appropriate, supporting their delivery of care. This study focused on the opinions of paediatric nurses, although the findings and recommendations have relevance to all fields of nursing.

\section{Limitations}

Paediatric nurses' weight status and health behaviours in this study were selfreported, although the tendency to present oneself in a more positive light when referring to weight, diet or exercise may mean that the proportion of respondents with negative health behaviours may be underestimated. The authors do not have any information on the health behaviours, attitudes or beliefs of non-respondents and the response rate was low (perhaps due to data being collected around the time of a largescale trust staff survey). However, the sample was relatively representative of the paediatric nurse population at the participating hospital trust and reported opinions are consistent with those found in other nursing samples (Blake and Harrison, 2013).

\section{Conclusions}

While paediatric nurses are concerned about rising rates of childhood obesity and recognise health promotion with children and their families as a key aspect of their role, they highlight current inadequacies in efforts to promote healthy eating in their clinical practice. There is a prevailing belief that paediatric nurses should be exemplars for the health behaviours they advocate to children and their families, and 
that their own lifestyle choices and health behaviours have the potential to impact negatively on the quality of patient care. These beliefs are inconsistent with paediatric nurses' self- reported health behaviours.

Future research might focus on: the development and evaluation of training interventions to instil confidence for the promotion of healthy eating in children and their families; developing resources that can be used with patients to support healthpromotion activities in a secondary care setting; and supporting paediatric nurses in adopting healthy lifestyle behaviours as role models for their patients. Mechanisms should be investigated for narrowing the cognitive dissonance between paediatric nurses' belief that they should present themselves as 'ideal' role models and their actual, contrasting health behaviours.

\section{References}

Bandura A (1986) Social Foundations of Thought and Action: a Social Cognitive Theory. Prentice Hall, Englewood Cliffs

Blake H (2013) Should nurses be role models for health? Nursing Times. 2 January. http://tinyurl.com/p8n2uth (accessed 8 January 2015)

Blake H, Harrison C (2013) Health behaviours and attitudes towards being role models. Br J Nurs 22(2): 86-94. doi 10.12968/bjon.2013.22.2.86 
Blake H, Malik S, Mo PKH, Pisano C (2011) 'Do as I say, but not as I do': are next generation nurses role models for health? Persp Pub Health 131(5): 231-9. doi $10.1177 / 1757913911402547$

Blake H, Mo PKH, Lee S, Batt ME (2012) Health in the NHS: lifestyle behaviours of hospital employees. Persp Pub Health 132(5): 213-15. doi

$10.1177 / 1757913912457309$

Borchardt G (2000) Said another way: role models for health promotion: the challenge for nurses. Nurs Forum 35(3): 29-32. doi 10.1111/j.17446198.2000.tb01002.x

Bull FC,Adams EJ, Hooper PL (2008) Well@Work: Promoting Active and Healthy Workplaces. Final Evaluation Report. Loughborough University

Chalmers K, Seguire M, Brown J (2002) Tobacco use and baccalaureate nursing students: a study of their attitudes, beliefs and personal behaviours. J Adv Nurs 40(1): 17-24. doi 10.1046/j.1365-2648.2002.02336.x

Department for Education and Skills (DfES) (2003) Every Child Matters. http://tinyurl.com/pl6jtee (accessed 8 January 2015)

Department of Health (2009) NHS Health and Wellbeing Review. Interim Report. The Stationary Office, London 
Department of Health (2011) Healthy Lives, Healthy People: A Call to Action on Obesity in England. http://tinyurl.com/kvtoopd (accessed 8 January 2015)

Friis K, Ekholm O, Hundrup YA, Obel EB, Gronbaek M (2007) Influences of health, lifestyle, working conditions and sociodemography on early retirement: The Danish Nurse cohort study. Scand J Pub Health 35(1): 23-30. doi: $10.1080 / 14034940600777278$

Hicks M, McDermott LL, Rouhana N, Schmidt M, Seymour MW, Sullivan T (2008) Nurses' body size and public confidence in ability to provide health education. J Nurs Schol 40(4): 349-54. doi 10.1111/j.1547- 5069.2008.00249.x

Malik S, Blake H, Batt M (2011) How healthy are our nurses? New and registered nurses compared. Br J Nurs 20(8): 489-96. doi 10.12968/ bjon.2011.20.8.489

Manojlovich M (2005) Promoting nurses' self-efficacy: a leadership strategy to improve practice. J Nurs Adm 35(5): 271-8

Marcus BH, Selby VC, Niaura RS, Rossi JS (1992) Self-efficacy and the stages of exercise behaviour change. Res Quart Exer Sport 63(1): 60-6. doi $10.1080 / 02701367.1992 .10607557$

Mayer C, Andrusyszyn MA, Iwasiw C (2005) Codman Award Paper: self- efficacy of staff nurses for health promotion counselling of patients at risk for stroke. Axone 26(4): 14-21 
Miller SK, Alpert PT, Cross CL (2008) Overweight and obesity in nurses, advanced practice nurses and nurse educators. J Am Acad Nurse Pract 20(5): 259-65. doi $10.1111 / \mathrm{j} .1745-7599.2008 .00319 . \mathrm{x}$

Nahm ES,Warren J, Zhu S,An M, Brown J (2012) Nurses' self-care behaviours related to weight and stress. Nurs Outlook 60(5): e23-e31. doi 10.1016/j. outlook.2012.04.005

Nursing Times (2008) How happy and healthy are nurses? http://tinyurl.com/ m9uu2zn (accessed 8 January 2015)

Nursing Times (2012) Obese NHS staff criticised at Lords. http://tinyurl.com/ cw98coc (accessed 8 January 2015)

Rash E (2008) Advanced practice nursing students' perceptions of health promotion. SOJNR 8(3): 1-11

Royal College of Physicians (RCP) (2013) Action on obesity: Comprehensive care for all. Report of a working party. RCP, London

Rush KL, Kee CC, Rice M (2005) Nurses as imperfect role models for health promotion. West J Nurs Res 27(2): 166-83; discussion 184-7 
Schwarzer R, Jerusalem M (1995) Generalized Self-Efficacy scale. In:Weinman

J,Wright S, Johnston M, eds. Measures in Health Psychology: a User's Portfolio.

Causal and Control Beliefs. NFER-NELSON,Windsor

\section{Key Points}

- Paediatric nurses report inadequacies in current healthy-eating promotion practice with children and their families

- Nurses feel that it is important to present themselves as role models for health, but this belief is inconsistent with their reported health behaviours

- Nurses feel their own health behaviours influence the quality of their healthpromotion practice, with regard to their confidence in promoting health and patients' willingness to heed their advice

- Education and training with access to evidence-based resources may help to increase confidence in integrating healthy-eating promotion in the care of children and their families

- Workplace health interventions may help to support paediatric nurses who wish to adopt healthy lifestyle choices health behaviours.

\section{Conflict of interest: none}


Box 1. Nurses' attitudes towards being role models for health

\begin{tabular}{|l|}
\hline Health promotion should be part of a paediatric nurse's job role \\
\hline $\begin{array}{l}\text { Sufficient promotion of healthy eating is undertaken in the wards/departments } \\
\text { where I work }\end{array}$ \\
\hline $\begin{array}{l}\text { Paediatric nurses are good role models for health to their patients and their } \\
\text { families }\end{array}$ \\
\hline I find it difficult to promote health behaviours if I do not carry them out myself \\
\hline My physical appearance affects the way I am perceived as a paediatric nurse \\
\hline Being an ideal weight is important for some roles as a paediatric nurse \\
\hline $\begin{array}{l}\text { Patients will find it easier to connect with me if they view my health behaviours } \\
\text { as those of a 'real' person rather than an ideal one }\end{array}$ \\
\hline $\begin{array}{l}\text { I feel under pressure to appear as a perfect role model to my patients and their } \\
\text { families }\end{array}$ \\
\hline Paediatric nurses should present themselves as role models for health \\
\hline $\begin{array}{l}\text { Patients will listen to my advice on health behaviours more if I appear to be } \\
\text { following that advice myself }\end{array}$ \\
\hline Paediatric nurses should have a healthy diet and exercise regularly themselves \\
\hline
\end{tabular}


Table 1. Barriers and facilitators for healthy-eating promotion

\begin{tabular}{|c|c|}
\hline Barriers & Facilitators \\
\hline Lack of knowledge and training & Adequate information and training \\
\hline Nurse having unhealthy lifestyle & Nurse having healthy lifestyle \\
\hline $\begin{array}{l}\text { Nurses as poor role models (e.g. obese } \\
\text { nurses) }\end{array}$ & $\begin{array}{l}\text { Nurse being 'visibly' good role model } \\
\text { (e.g. healthy weight) }\end{array}$ \\
\hline Nurse's negative values and attitudes & Nurse's positive values and attitudes \\
\hline Not perceived to be part of nurse's role & Perceived to be integral to nurse's role \\
\hline $\begin{array}{l}\text { Not perceived to be a priority by senior } \\
\text { staff }\end{array}$ & $\begin{array}{l}\text { Allocated time for health promotion } \\
\text { Adequate patient/family contact }\end{array}$ \\
\hline $\begin{array}{l}\text { Lack of time (e.g. low staffing levels, } \\
\text { heavy workload, missing breaks) }\end{array}$ & $\begin{array}{l}\text { Good relationships with parents/family/ } \\
\text { patient }\end{array}$ \\
\hline Quick turnover of patients & Nursing being respected profession \\
\hline Negative parent/family attitudes & Ability to refer to other professionals \\
\hline $\begin{array}{l}\text { Sensitivity of the subject } \\
\text { No facilities to refer on to }\end{array}$ & $\begin{array}{l}\text { Having appropriate information to give } \\
\text { to children and families }\end{array}$ \\
\hline Lack of personal confidence & Personal confidence \\
\hline Lack of experience & Support from others \\
\hline Not enough support from dieticians & Personal motivation to promote health \\
\hline $\begin{array}{l}\text { Shift patterns/tiredness } \\
\text { Lack of healthy food in the hospital/on } \\
\text { the ward }\end{array}$ & $\begin{array}{l}\text { Healthier menu options in the hospital/ } \\
\text { on the ward }\end{array}$ \\
\hline
\end{tabular}

